\title{
Mifepristone (RU 486) treatment of meningiomas
}

S W J Lamberts, H L J Tanghe, C J J Avezaat, R Braakman, R Wijngaarde, J W Koper, F $\mathrm{H}$ de Jong

\begin{abstract}
Meningiomas are common brain tumours which are generally benign, well circumscribed and slow growing. In a minority of patients complete surgical removal is not possible and re-growth of tumour tissue is a major clinical problem. Most meningiomas contain progesterone receptors. The anti-progestational drug mifepristone (RU 486) binds to these receptors. Ten patients were treated with 12 recurrent or primary "inoperable" meningiomas, all of whom had shown recent neuroradiological and/or ophthalmological evidence of tumour growth. They received $200 \mathrm{mg}$ mifepristone daily for 12 months. Most patients initially had complaints of nausea, vomiting and/or tiredness. In four patients prednisone ( $7.5 \mathrm{mg} /$ day) was given after which these side-effects subsided. CT scan analysis of tumour size, showed progression of growth of five meningiomas in four patients, stable disease in three patients with three tumours and regression of four tumours in three patients. A decrease in the complaints of headache and an improved general well being was observed in five patients. Two patients died during the treatment period from unrelated causes. Mifepristone treatment resulted in control of tumour growth (= stable disease) in six of 10 patients who had shown recent evidence of tumour growth. In three of these six patients consistent tumour shrinkage was observed.
\end{abstract}

Meningiomas occur more frequently in women than in men. ${ }^{1}$ Previous clinical and epidemiological studies suggest that these tumours often grow during pregnancy, ${ }^{2}$ while an association between breast cancer and meningiomas has been reported. ${ }^{3}$ These observations suggest a biological role of female sex steroids in the regulation of the growth of meningiomas. Indeed, progesterone, but not oestradiol receptors have been found in virtually all meningiomas, both from female and male patients. ${ }^{4-9}$ The first clinically available progesterone receptor antagonist mifepristone (RU 486) has been shown to bind to the progesterone receptors in meningiomas. ${ }^{9}$ Both studies with cultured meningioma cells or explants and with nude mice carrying meningioma tissue suggest that hormonal manipulation can influence growth in part of the tumours. ${ }^{10-17}$ Our own culture studies indicate that progesterone increases the sensitivity of cultured meningioma cells to mitogenic stimuli, while mifepristone counteracts these stimulating effects. ${ }^{18}$ Preliminary studies of treatment of meningioma patients with medroxyprogesterone acetate, tamoxifen, and LHRH analogs suggest that the growth of meningiomas in a minority of patients can be controlled. ${ }^{19-22}$

In this study we investigated the effect of therapy with mifepristone ( $200 \mathrm{mg} /$ day) for 12 months on 10 meningiomas patients who showed neuroradiological and/or ophthalmological evidence of recent progressive tumour growth.

\section{Patients and methods}

Patients and experimental protocol

In this study 10 patients with single or multiple meningiomas were investigated (table). Apart from patient 10, all females were menopausal. In all patients there was neuroradiological evidence (nine patients) and/or ophthalmo-

Table Patient data

\begin{tabular}{|c|c|c|c|c|}
\hline & $M / F$ & Age & $\begin{array}{l}\text { Phenytoin } \\
\text { therapy }\end{array}$ & Localisation meningioma, size at start $\left(\mathrm{cm}^{3}\right)$, previous therapy, recent growth \\
\hline $\begin{array}{l}1 \\
2\end{array}$ & $\mathbf{F}$ & $\begin{array}{l}71 \\
53\end{array}$ & - & $\begin{array}{l}\text { Tuberculum sellae (right): } 8.3 \mathrm{~cm}^{3} \text {; continuous growth since } 2 \text { years, blindness right eye } \\
\text { Inner ridge (left) and tentorium (left) of } 10.2 \text { and } 5.3 \mathrm{~cm}^{3} \text {; slow, persistent growth since } 1.5\end{array}$ \\
\hline 3 & $\mathbf{M}$ & 63 & + & $\begin{array}{l}\text { Inner/middle ridge (left): } 67.4 \mathrm{~cm}^{3} \text {; previous operations } 1972,1982,1986 \text {; rapid } \\
\text { progressive growth, visual loss left eye }\end{array}$ \\
\hline 4 & $\mathbf{F}$ & 72 & + & $\begin{array}{l}\text { Frontal: } 66.5 \mathrm{~cm}^{3} \text { : previous operations } 1965,1981 \text {; continuous growth since } 6 \text { years; slow } \\
\text { affect: epilepsy }\end{array}$ \\
\hline 5 & $\mathbf{F}$ & 48 & - & $\begin{array}{l}\text { Suprasellar: } 28 \mathrm{~cm}^{3} \text { : previous operation } 1978 \text {; tumour size unchanged since } 8 \text { years; } \\
\text { blindness right eye, progressive visual loss left eye }\end{array}$ \\
\hline $\begin{array}{l}6 \\
7\end{array}$ & $\begin{array}{l}\mathbf{M} \\
\mathbf{M}\end{array}$ & $\begin{array}{l}54 \\
68\end{array}$ & + & $\begin{array}{l}\text { Parasagittal (right): } 68.7 \mathrm{~cm}^{3} \text {; previous operation } 1974 \text {; continuous growth since } 2 \text { years } \\
\text { Sphenoid (right) with infratemporal and intraorbital extension: } 164 \mathrm{~cm}^{3} ; \text { previous } \\
\text { operations } 1973,1986 \text {; blindness right eye and continuous growth since } 2 \text { years; proptosis } \\
\text { right eve }\end{array}$ \\
\hline 8 & $\mathbf{F}$ & 64 & - & $\begin{array}{l}\text { Parasellar (left) at apex left opticus }\left(9 \cdot 6 \mathrm{~cm}^{3}\right) \text {; continuous growth since } 3 \text { years, progressive } \\
\text { visual loss left eye, proptosis left eye }\end{array}$ \\
\hline 9 & $\mathbf{F}$ & 53 & - & $\begin{array}{l}\text { Sphenoid (left) with para-sellar, sellar and infratemporal extension: } 89.5 \mathrm{~cm}^{3} \text {; previous } \\
\text { operations } 1983 \text { and } 1987 \text {; rapid growth since } 2 \text { years; tumour palpable in upper jaw, } \\
\text { hypopituitarism, treated with hydrocortisone ( } 30 \mathrm{mg} / \text { day) }\end{array}$ \\
\hline 10 & $\mathbf{F}$ & 32 & + & $\begin{array}{l}\text { Fale (left) and cerebellar/tentorium (right) tumours of } 25.3 \text { and } 21.5 \mathrm{~cm}^{3} \text {; bilateral } \\
\text { acousticus neurinomas, bilateral opticus tumours, previous operation in } 1987\end{array}$ \\
\hline
\end{tabular}


logical evidence of recent progressive tumour growth (patients $1,2,3$ and 5). In seven patients this was tumour progression or recurrence after previous operation(s), while three patients had not had a previous operation. All patients had been selected by at least two independent neurosurgeons of the staff of the department of neurosurgery of the University Hospital Rotterdam because: a) Reoperation was not expected to completely remove the tumour; b) The localisation of the tumour caused a high risk of severe complications during/after surgery; c) The general condition of the patient was so poor, that surgery seemed contraindicated (patients 3 and 4). Exclusion criteria were pregnancy, the use of oral contraceptives, patients with a very poor performance status, signs or symptoms of an elevated intracranial pressure, coexistent psychiatric diseases, other cancer, renal and liver insufficiency.

The experimental protocol had been approved by the ethical committee of the University Hospital Rotterdam. All patients signed an informed consent form in which the seriousness of their disease and the unknown effects of mifepristone therapy were explained.

According to the experimental protocol the patients were treated for 12 months with 200 mg mifepristone daily. If side effects or signs of (relative) adrenocortical insufficiency developed, a daily dose of $7.5 \mathrm{mg}$ prednisone would be added to mifepristone therapy. Clinical evaluation was done every two to three weeks during the first three months and every two months during the second part of the study. If visual abnormalities existed, the patients were also followed on a regular basis by an ophthalmologist. Side effects were carefully noted and ECGs, measurement of blood pressure and routine clinical chemical determinations were carried out at least four times during the investigation period.

\section{CT scanning and analysis of tumour size}

The size of the meningiomas was measured repeatedly with the same Philips Tomoscan 310 apparatus. Tumour volume was calculated by $\mathrm{CT}$ planimetry independently by the same neuroradiologist (HT) and neurosurgeon (RB) under the same conditions. The thickness of the slices was kept constant at $3 \mathrm{~mm}$. Measurement of the planar surface of the tumour in each slice was calculated by computer after circling the outer border. All calculated surfaces were added to calculate the volume of the tumour. If hyperostotic bone was present at the surface of the tumour, this was added in a constant manner as part of the tumour. This also applied to the cavernosus sinus in the few cases were no sharp margin with the tumour could be determined. Repeated measurement by a given neuroradiologist of the same tumour on the same CT scan had an error rate of $<5 \%$.

\section{Results}

1) Tolerance/side effects

Mifepristone caused no or minimal transient side effects in six patients: nausea and anorexia occurred for a period of a few days to up to two weeks in three patients, while three patients took the drug without side effects. The other four patients $(2,3,4$ and 6$)$, however, experienced more severe complaints of nausea (4) and recurrent attacks of vomiting (3) starting during the first week of therapy. In addition these four patients felt exhausted and anorectic. In patient 4 prolonged vomiting stopped on the third day of mifepristone therapy, shortly after the start of the simultaneous administration of $7.5 \mathrm{mg}$ prednisone daily. In patients 2, 3 and 6 these complaints persisted and concomitant prednisone therapy $(7.5 \mathrm{mg})$ was started after three weeks. Thereafter these complaints subsided, but prednisone therapy was continued in all four patients throughout the study. No changes in blood pressure (supine and/or standing) were noted during mifepristone treatment for up to one year. Also ECG and routine clinical chemical investigations did not show changes. These included the measurements of fasting glucose, potassium, chloride and sodium concentration in serum, renal and liver functions, as well as haemoglobin, haematocrit, white blood cell and thrombocyte counts. Body weights did not change significantly in these 10 patients during mifepristone treatment.

2) Changes in tumour size and tumour related complaints during treatment

Mifepristone resulted in a general improvement of well being in four patients $(1,7,8$ and 9). Especially complaints of headaches and/or tension in the jaw, skull or eye improved or disappeared in five patients. In patient 2 the visual acuity of the left eye improved slightly, while in patient 8 the palpable part of the soft tissue mass in the upper jaw shrank considerably. The proptosis of one eye in patients 7 and 8 did not change during mifepristone treatment. In patient 5 , however, the already very bad visual acuity of the remaining eye further deteriorated during therapy.

Changes in tumour volume were measured in these 10 patients by CT scanning at regular intervals during and after mifepristone therapy (figure). In four patients clear growth of five meningiomas was observed during therapy. Two of these patients died during this period. Fourteen months before the start of therapy patient 3 had undergone a coronary bypass operation because of longstanding angina. In parallel he developed progressive visual loss of the left eye, aphasia, headaches, paresis of the right arm, while he could no longer walk because of loss of equilibrium. These symptoms were attributed to a rapidly growing meningioma in the inner and middle ridge with intra-orbital expansion on the left side. The initiation of mifepristone therapy resulted in side effects (see above), which were well controlled by prednisone $(7.5 \mathrm{mg} /$ day $)$. There were no complaints of headaches. Precordial pains were controlled with beta-blocking agents. No signs or symptoms of congestive heart failure were observed. After 4.5 months of mifepristone therapy he developed pulmonary oedema and a period of ventricular 
Figure The course of tumour size before, during and after mifepristone (200 mg/day) treatment of 10

patients with inoperable primary or recurrent meningiomas. Top: five tumours in four patients which showed growth; middle: three tumours in three patients which remained stable and bottom: four tumours in three patients which showed (transient) decrease in size. (The numbers correspond to the patient numbers in the table, on the $x$-axis time is expressed in months, before (-) and after (+) therapy).

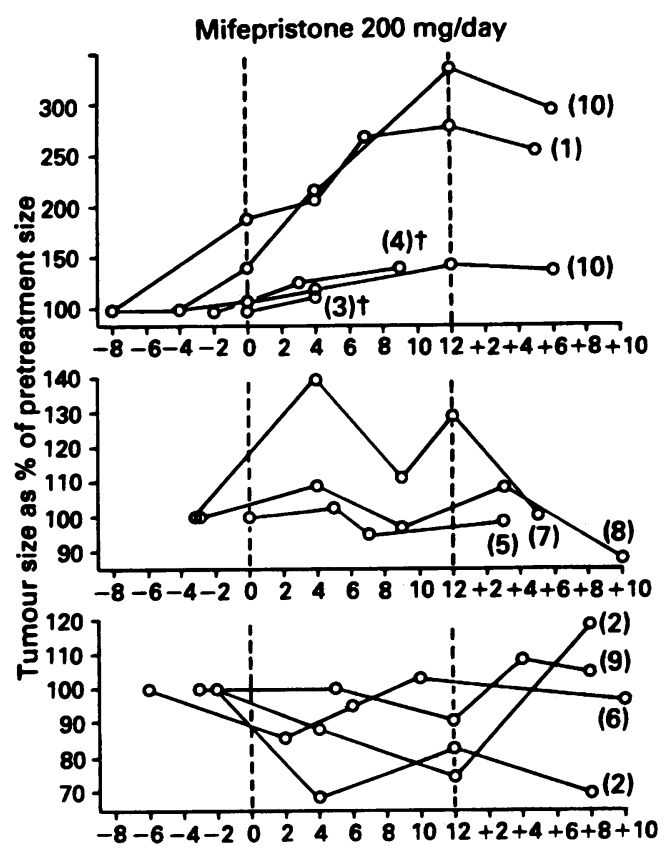

fibrillation was treated by defibrillation. No evidence of an acute myocardial infarction was found. After four months of treatment the size of the meningioma had further increased from $67 \cdot 4$ to $77 \cdot 4 \mathrm{~cm}^{3}$ ( $+15 \%$ ). This patient died after 5.5 months of mifepristone treatment from sudden asystole.

Patient 4 had a frontal meningioma and severe flattened affect. Her skull was open with local uncontrollable inflammation after the removal of a large piece of osteomyelitic bone at a previous operation. She often experienced small epileptic fits despite therapy with phenytoin. These attacks did not change after the start of mifepristone therapy. The tumour progressively increased in size from 66.5 to 80.8 after three months and to $90 \mathrm{~cm}^{3}$ after nine months of treatment. After 12 months of therapy this patient died at home from a severe epileptic attack. In patient 1 an inner ridge meningioma on the right side had nearly doubled in size in the eight months before the start of mifepristone treatment (from 4.4 to 8.3 $\mathrm{cm}^{3}$ ). Thereafter, a further progressive rise in tumour size to maximally $12 \cdot 2 \mathrm{~cm}^{3}$ (at 12 months) was observed. Patient 10 was exceptional in that she has neurofibromatosis type 2 . Apart from bilateral acoustic neurinomas and bilateral opticus tumours she had multiple meningioma-type tumours along the falx cerebri and the tentorium. One tentorium meningioma on the right side and a falx meningioma on the left side showed progressive further growth during mifepristone therapy.

The meningiomas of patients 5,7 and 8 showed evidence for a stabilisation of tumour growth during and also in the period after stopping mifepristone treatment (figure, middle section). All three tumours initially still increased in size during the first months of therapy, but thereafter shrinkage and/or stabilisation of size was seen.

In patients 2, 6 and 9 (transient) decrease in tumour size was observed during mifepristone treatment (the fig. lower section). The right parasagittal meningioma of patient 6 only transiently decreased in size after two months of treatment, while the huge sphenoid meningioma with considerable extension in the infratemporal fossa and into the pituitary fossa of patient 9 also transiently decreased in size. This was accompanied by an impressive clinical improvement in this patient throughout the 12 month treatment period with disappearance of pain and swelling of the jaw. In patient 2 both a parasellar and a tentorium meningioma decreased in size, while the visual acuity of the left eye improved.

\section{Discussion}

Meningiomas are common tumours of the arachnoidea, which account for about $20 \%$ of intracranial tumours. ${ }^{23}$ They are generally benign, well circumscribed, and slow growing. They can, however, be accompanied by invasion of the bone and/or encasement of major blood vessels, or they may grow to massive proportions, compromising the likelihood of total surgical removal. In addition multiple meningiomas occur in $5-10 \%$ of patients. The primary and central role of surgery in the treatment of meningiomas is well-established and the operative and long-term mortality rates have considerably declined over the past decades. ${ }^{24}$ However, the likelihood of complete resection of meningiomas is determined in part by the tumour site. ${ }^{25}$ For example, convexity meningiomas can be removed easily in most instances and have a low recurrence rate $(3 \%$ after five years ${ }^{25}$ ), while the operative results of parasellar and sphenoid ridge meningiomas are less impressive and show a much higher incidence of recurrence $(19 \%$ and $34 \%$, respectively ${ }^{25}$ ). Medical treatment which might slow or inhibit tumour growth would be of benefit especially in these last categories of patients.

The discovery that a majority of human meningiomas contain high numbers of high affinity progesterone binding sites was the basis for new thoughts and hypotheses concerning a medical therapy of meningiomas. ${ }^{410}$ Subsequently, it was shown that the anti-progestin mifepristone has the same affinity for the progesterone receptor of meningiomas, as does, for example R5020, a known progesterone analog and binder of the progesterone receptor. ${ }^{96}$ Preliminary studies on cultured meningioma cells indicated a certain degree of hormonal dependency of these tumour cells, although this was not uniformly found. Stimulation of the growth of meningioma cells in the presence of physiologically relevant progesterone concentrations was observed in some but not all tumour cell cultures. ${ }^{10-18}$ Interestingly, mifepristone caused inhibition of cell growth and of thymidine incorporation in several tumours. ${ }^{21}$ Our own studies indicate that progesterone causes only minimal effects on the growth of cultured meningioma tissue (cells or explants), but that progesterone modulates the stimulatory response of cultured human meningioma cells to epidermal growth 
factor and other growth factors, while mifepristone blocks this enhancing effect of progesterone. ${ }^{18}$ This suggests that the presence of progesterone in the culture medium increases the sensitivity of meningioma cells to mitogenic stimuli, whereas mifepristone counteracts these stimulating effects of progesterone.

In vivo studies with nude mice carrying transplanted human meningiomas tissue indicated a growth inhibitory effect of mifepristone. ${ }^{17}$ Such a tumour growth inhibitory effect of the drug was also observed in several other hormone-dependent tumour models, ${ }^{27-30}$ while (transient) tumour growth inhibition was reported in a minority of breast cancer patients. $^{3132}$

Medical therapy of meningioma patients with the progesterone agonist/antagonist medroxyprogesterone, with tamoxifen or with an LHRH analog resulted in varying, but in some cases encouraging results. ${ }^{19-22}$

The results of therapy with mifepristone in the present 10 meningioma patients were not dramatic. All patients had been selected on the basis of recent (mostly neuroradiological) evidence of growth of the tumours. The previous histories of these patients showed that they represented a group of aggressively growing meningiomas. In four patients we observed a further growth of the meningioma during mifepristone therapy, without evidence of inhibition of growth by the drug. Two of these patients died during mifepristone treatment: one from a pre-existing cardiovascular complication and one from pre-existing epilepsy. We do not know whether these intercurrent deaths were directly tumour-related, but we also do not have evidence that they were treatmentrelated. The initial complaints of nausea, tiredness and vomiting which occurred in some of the patients during the first period of mifepristone therapy was interpreted as relative adrenal insufficiency which was caused by the cortisol receptor blocking activity of the drug. Extensive endocrine studies in these patients during mifepristone therapy have been published in a separately. ${ }^{33}$ The two meningiomas of patient 10 showed a rapid growth both before and during mifepristone treatment. This patient had the rare syndrome of neurofibromatosis type 2, consisting of bilateral acoustic neurinomas, bilateral optic tumours and multiple meningiomas, which is related to a genetic abnormality, involving chromosome $22 .{ }^{3435}$ In the other six patients a total of seven meningiomas showed stabilisation or slight regression of tumour growth during mifepristone treatment. In patient 5 this therapy can be considered as a failure because the already very low visual acuity of her remaining eye further deteriorated, although no change in tumour size was observed during therapy. In three patients a (transient) decrease in tumour size was observed. Medical therapy was accompanied by a decrease in headaches in five patients, an increase in the feeling of general well being in four, a slight improvement in visual acuity of one eye in one (patient 2), and a decrease in palpable tumour size in one patient (patient 9). Stable disease and/or slight tumour shrinkage in six of 10 patients (seven of 12 meningiomas) during mifepristone therapy was in our opinion of special value (except in patient 5 who showed visual loss), because all patients had been selected because of recent evidence of tumour growth.

Our study suffers from methodological shortcomings which makes it only an observational one. Apart from the low number of patients studied, the size, location and duration of existence of the tumours varied considerably. Most importantly, there was no placebo or control arm, which makes definite conclusions on the beneficial effects attributed to mifepristone doubtful at present.

A further shortcoming of this study is that we do not have data on the presence and the affinity of progesterone receptors on these tumours. This might be of importance, because in a preliminary study involving a group of 24 meningioma patients ${ }^{36}$ we showed that there is an inverse relationship between the number of progesterone receptors and CT scan characteristics of these tumours which indicate regressive behaviour (for example, the presence of necrosis, cyst formation and/or intratumoural haemorrhage). This might mean that medical treatment of meningioma patients with progesterone receptor blocking drugs is beneficial and effective especially in those patients harbouring meningiomas with a relatively "low degree of aggression", which might mean those tumours which do not grow very fast.

In conclusion, preliminary evidence has been presented that therapy with the progesterone receptor blocking drug mifepristone (RU 486) results in control of tumour growth in some meningioma patients. Mifepristone caused considerable side effects, however, and new more specific anti-progestins (with less glucocorticoid-receptor blocking activity) might be better tolerated and therefore more attractive compounds to use in follow up studies (phase 2). Also future studies should be placebo-controlled and include patients in whom the progesterone receptor content of the meningiomas is known.

1 Quest DO. Meningiomas: an update. Neurosurg 1978;3: 219-25.

2 Bickerstaff ER, Small JM, Guest IA. The relapsing course of certain meningiomas in relation to pregnancy and men-
struation. $\mathcal{F}$ Neurol Neurosurg Psychiatry 1958;21:89-91.

3 Schoenberg BS, Christine BW, Whisnant JP. Nervous system neoplasms and primary malignancies of other system neoplasms and primary malignancies of other
sites. The unique association between meningiomas and sites. The unique association between menin
breast cancer. Neurology 1975;25:705-23.

4 Poisson M, Pertuiset BF, Hauw JJ, et al. Steroid hormone receptors in human meningiomas, gliomas and brain receptors in human meningiomas, gliom
metastases. $f$ Neuro-Oncol 1983;1:179-89.

5 Schnegg, JF, Gomez F, Lemarchand-Beraud T, de Tribolet N. Presence of sex steroid hormone receptors in meningioma tissue. Surg Neurol 1981;15:415-8.

6 Magdelenat H, Pertuiset BF, Poisson M, et al. Progestin and oestrogen receptors in meningiomas. Biochemical characterization, clinical and pathological correlations in $\mathbf{4 2}$ cases. Acta Neurochir 1982;64:199-213.

7 Yu ZY, Wrange O, Haglund B, et al. Estrogen and progestin receptors in intracranial meningiomas. $f$ Steroid Biochem 1982;16:451-6.

8 Blankenstein MA, Blaauw G, Lamberts SWJ, et al. Presence of progesterone receptors and absence of oestrogen Eur $\mathcal{f}$ Cancer Oncol 1983;19:365-70.

9 Blankenstein MA, Blaauw G, Lamberts SWJ. Progestin and estrogen receptors in human meningioma. Clin Neuropharmacol 1984;7:363-7. 
10 Olsen JJ, Beck DW, Schlechte J, Loh PM. Hormonal manipulation of meningiomas in vitro. $\mathcal{f}$ Neurosurg 1986;65:99-107.

11 Zava DT, Markwalder TM, Markwalder RV. Biological expression of steroid hormone receptors in primary meningioma cells in monolayer culture. Clin Neuropharmacol 1984:7:382-8.

12 Jay JR, MacLaughlin DT, Riley RR, et al. Modulation of meningioma cell growth by sex steroid hormones in vitro. f Neurosurg 1985;62:757-62

13 Weisman AS, Villemure JG, Kelly PA. Regulation of DNA synthesis and growth of cells derived from primary human meningiomas. Cancer Res 1986;46:2545-50.

14 Markwalder TM, Gerber HA, Waelti E, et al. Hormonotherapy of meningiomas with medroxyprogesterone acetate: immunohistochemical demonstration of the effect of MPA on growth fractions of meningioma cells using the monoclonal antibody Ki-67. Surg Neurol 1988;30: 97-101.

15 Markwalder TM, Waelti E, Koenig MP. Endocrine manipulation of meningiomas with medroxyprogesterone acetate. Effect of MPA on receptor status of meningioma cytosols. Surg Neurol 1987;28:3-9.

16 Waelti ER, Markwalder TM. Endocrine manipulation of meningiomas with medroxyprogesterone acetate. Surg Neurol 1989;31:96-100.

17 Olsen JJ, Beck DW, Schleckte JA, Loh PM. Effect of the antiprogesterone RU-38486 on meningioma implanted into nude mice. $\mathcal{F}$ Neurosurg $1987 ; 66: 584-7$.

18 Koper JW, Foekens JA, Braakman R, Lamberts SWJ. Effects of progesterone on the response to epidermal growth factor and other growth factors in cultured human meningioma cells. Cancer Res 1990;50:2604-7.

19 Jääskeläinen J, Laasonen E, Kärkkäinen H, et al. Hormone treatment of meningiomas: lack of response to medroxyprogesterone acetate (MPA). Acta Neurochir 1986;80: 35-41.

20 Markwalder TM, Seiler RW, Zava DT. Endocrine manipulation of inoperable and recurrent meningiomas - a pilot study. Proc 13th International Congress of Chemotherapy. Study. Proc 13th International Congr

21 Blankenstein MA, van 't Verlast JW, Croughs RJM. Hormone dependency of meningiomas. Lancet 1989;i:1381.

22 Markwalder TM, Waelti E, Koenig MP. Endocrine manipulation of meningiomas with medroxyprogesterone acetate. Effect of MPA in receptor status of meningioma cytosols. Surg Neurol 1987;28:3-9.

23 Hoessly GF, Olivecrona H. Report on 280 cases of verified parasagital meningioma. $\mathcal{f}$ Neurosurg $1955 ; 12: 614-26$.

24 Maxwell RE, Chou SN. Preoperative evaluation and man- agement of meningiomas. In: Schmidek HR, Sweet WH, eds. Operative neurosurgical techniques. Indications, methods and results, Vol 1 . New York: Grune and Stratton, 1982;481-9.

25 Mirimanoff RO, Dosoretz DE, Longgood RM, et al. Meningioma: analysis of recurrence and progression following neurosurgical resection. $f$ Neurosurg 1985;62:18-24.

26 Blaauw G, Blankenstein MA, Lamberts SWJ. Sex steroid receptors in human meningiomas. Acta Neurochir 1986;79:42-7.

27 Lamberts SWJ, Uitterlinden P, Bons EG, Verleun T. Comparison of the actions of RU 38486 and megestrol acetate in the model of a transplantable adrenocorticotropin- and prolactin-secreting rat pituitary tumor. Cancer Res 1985;45:1015-9.

28 Lamberts SWJ, van Koetsveld P, Verleun T. Prolactin release-inhibitory effects of progesterone, megestrol ace-
tate, and mifepristone (RU 38486) by cultured rat pituitary tumor cells. Cancer Res 1987;47:3667-71.

29 Bakker GH, Setyono-Han B, Henkelman MS, et al. Comparison of the actions of the antiprogestin mifepristone (RU 486), the progestin megestrol acetate, the LHRH analog buserelin, and ovariectomy in treatment of rat mammary tumors. Cancer Treat Rep 1987;71:1021-7.

30 Bardon S, Vignon F, Chalbos D, Rochefort H. RU 486, a progestin and glucocorticoid antagonist, inhibits the growth of breast cancer cells via the progesterone recepter. f Clin Endocrinol Metab 1985;50:692-7.

$31 \mathrm{Klijn}$ JGM, de Jong FH, Bakker GH, et al. Antiprogestins, a new form of endocrine therapy for human breast cancer. Cancer Res 1989;49:2851-6.

32 Romieu G, Maudelonde T, Uhlmann A, et al. The antiprogestin RU 486 in advanced breast cancer: preliminary clinical trial. Bull Cancer 1987;74:455-61.

33 Lamberts SWJ, Koper JW, de Jong FH. The endocrine effects of long-term treatment with mifepristone (RU 486). $¥$ Clin Endocr Metab 1991;73:187-91.

34 Seizinger BR, Martuza RL, Gusella JE. Loss of genes on chromosome 22 in tumorigenesis of human acoustic neuroma. Nature 1986;322:644-7.

35 Seizinger BR, de la Monte S, Atkins L, et al. Molecular genetic approach to human meningioma: loss of genes on chromosome 22. Proc Natl Acad Sci USA 1987;84: 5419-23.

36 Huisman TWA, Tanghe HLJ, Koper JW, et al. The relationship between the presence of progesterone, estradiol, somatostatin and epidermal growth factor receptors of human meningiomas and their CT characteristics. Eur $\mathcal{f}$ Cancer 1991;27:1453-7. 